\title{
Efficiency of the RES Hybrid Microinstallations Working in Energy Clusters
}

\author{
Stawomir Sowa ${ }^{1, *}$ \\ ${ }^{1}$ Institute of Electric Power Engineering, Faculty of Electrical Engineering Poznan University of \\ Technology, Poland
}

\begin{abstract}
The energy sector is constantly changing. Electromobility, improvement of energy efficiency, smart cities these are just some of the challenges that the present power industry is facing. The main goal for the power industry is to ensure the energy security of its customers, to develop low-community technologies which are mainly based on renewable energy sources and local raw materials. The transition from a centralized energy sector based mainly on conventional power plants to a distributed energy sector requires constant control and management of the generation and demand for energy. One of the solution existing since 2016 are energy clusters. The concept of their functioning is based on the civil-law agreement of locally operating entities that produce, sell, store and consume electricity, heat and cold. The main purpose of introducing energy clusters is the development of distributed energy. Energy clusters ensure the improvement of local energy security with relatively low outlays and low environmental impact. Technological development and installations based on renewable energy sources make energy clusters a beneficial and cost-effective solution for local energy sector. The article presents the idea of energy clusters functioning, and describes the current status of development. It also includes the hybrid systems characteristics of RES systems as an effective source of energy. The conclusion includes the legitimacy of the energy cluster development based on RES installations.
\end{abstract}

\section{Introduction}

In recent years, the concept of centralised, high-capacity power engineering, based mainly on fossil fuels, has undergone significant changes. This results from the intensive exploitation of fossil resources, their slow depletion and the development of modern technology in dispersed power engineering. Energy efficiency is associated with the introduction of measures aimed at reducing the consumption of final energy. There are many ways to achieve this. The final energy supplied to our buildings is mostly produced in conventional power plants. The use of renewable energy sources ensures the supply of energy produced from a free source such as sun, water or wind.

The use of hybrid power generation systems increases productivity by ensuring that energy is supplied to the system at different times and under different atmospheric

\footnotetext{
* Corresponding author: Slawomir@sowa.poznan.pl
} 
conditions. Energy clusters bring together different energy producers and consumers within their borders. Using generators with small installations and micro installations of RES with the possibility of controlling the flow of energy in the energy cluster, we can achieve big savings.

Thanks to such solutions we can significantly reduce the consumption of energy generated in conventional sources, i.e. power plants or combined heat and power plants. Production of energy, which can be distributed in the area of the energy cluster, concerns mainly electricity. In 2018, $208.5 \mathrm{GWh}$ of electricity was generated in small RES installations in Poland. 142.3 GWh were introduced to the distribution network [1]. This means that $32 \%$ of the electricity generated in small RES installations is used for own needs, and the vast majority of it, i.e. $68 \%$, is transferred to the distribution network. Energy producers who use the generated energy for their own needs and return the surplus to the grid are called prosumers. Energy prosumers are characterised by great care for the environment and are involved in activities for the benefit of nature protection. The construction of installations that generate more power than their own needs results from the assumption, increased demand for energy in the future, the inability to store energy generated when it is not possible to consume it and high environmental awareness. In addition, when making decisions on construction, we are guided by the economic factor, which is more advantageous in the case of larger generation systems. Another argument in favour of building an installation generating more energy than its own needs is the possibility to take advantage of various forms of co-financing and tax discounts. Figure 1 shows the electricity generated in Poland in small RES installations in 2018, broken down by type of installation [1].

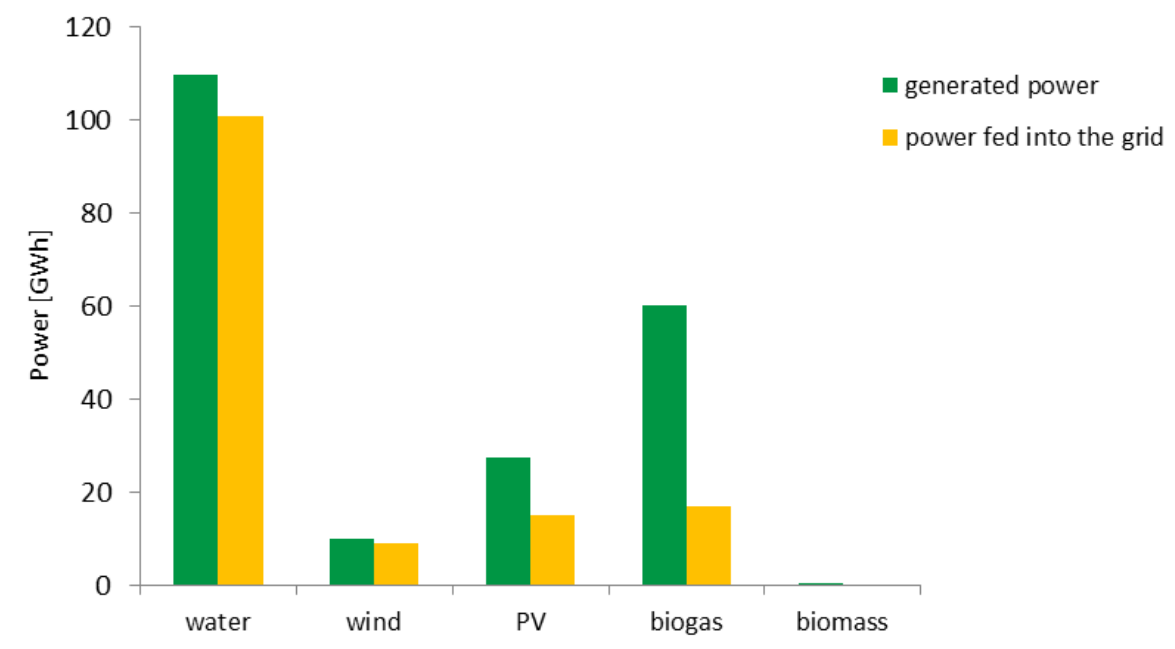

Fig. 1. Energy generated in various small RES installations and distributed in Poland in 2018.

\subsection{Energy efficiency}

The concept of energy efficiency is contained in the regulations of the Act [2]. It is defined as the relation of the size of the achieved effect for example in the case of an installation to the amount of energy consumed by the given object or installation in order to achieve this effect. The less energy is used to achieve the effect, the higher efficiency is. In a situation where the energy is supplied from renewable energy sources, we can say that at the same time we limit the amount of energy taken from the external grid, i.e basically the energy produced in Poland mainly by conventional power plants. The less energy taken 
from an external supplier, and the more energy we generate from RES, the greater the efficiency of the facility is achieved. The modern low-energy facilities are designed in a way that ensures low energy consumption while ensuring energy production by our own systems, which are mostly based on renewable energy sources. The use of RES to increase the energy efficiency of the facilities is a common and popular solution [3].

Undertaking the actions related to the reduction of final energy consumption is also included in the European Union directives [4]. According to this directive, the EU member states are obliged to implement measures that will reduce the final energy consumption by $1.5 \%$ per year. Introducing solutions that lead to energy savings, including the reduction of energy consumption generated by conventional power plants, is a beneficial measure. It provides financial savings in energy payments and helps to care for the natural resources of the earth and reduce the emission of toxic $\mathrm{CO}_{2}[5,6]$.

\subsection{Small and micro-hybrid RES installations}

The classification of micro or small RES installations is determined by the amount of the produced energy. The Act [7] specifies micro installations of a renewable energy source with a total installed electrical power of over $40 \mathrm{~kW}$ but not exceeding $200 \mathrm{~kW}$. On the other hand, small RES installations are such installations that generate electricity with a capacity not exceeding $600 \mathrm{~kW}$. Hybrid installations are the systems of renewable energy sources that produce electricity or electricity and heat in at least two installations using different energy carriers. Hybrid systems are more efficient because they can provide power generation from one installation while the other is not capable to produce the energy. Examples are wind turbine and PV photovoltaic systems [7]. When there is no sun, e.g. at night, when the PV system does not generate any energy, a wind turbine can generate electricity by operating independently. Such a combination of independent generation systems increases the generation stability of the generative system and consequently reduces the consumption of electricity from other external suppliers. We can achieve an even better effect on the long-term energy demand of the facility by using energy storage facilities. Such systems provide even greater energy independence, but due to their relatively high costs, they are currently less popular.

\section{Energy clusters}

The term: energy cluster was defined by the RES Act [8]. According to this act, it is a civillaw agreement, which may include individuals as well as institutes and local government units. Distribution and trading of energy generated from RES takes place within the network of rated voltage not exceeding $110 \mathrm{kV}$. Energy clusters are concentrated in the area of up to 5 urban communes or one district.

Within the energy clusters there are entities that generate, control and trade in energy produced mainly from renewable energy sources. The concept of energy clusters is part of the idea of dispersed energy development, whose savings are obtained from the location of energy generation sources, which are located near the recipient [9]. Energy clusters as fullyfledged entities on the power market ensure optimal use of local energy resources. They create effective mechanisms that are competitive for the centralised energy policy of the country. There are 66 energy clusters in Poland.

\subsection{The concept of energy clusters}

Energy clusters are primarily aimed to support the development of distributed energy to ensure local power engineering security. The implementation of this objective is intended to 
be environmentally friendly and, at the same time, to ensure energy and economic efficiency. Achieving these goals can be accomplished by implementing the latest useful and cost-effective technologies. Clusters are to provide optimal organizing, legal and financial conditions for the cooperation of their members. They should base on the local resources and local energy and economic potential. It is assumed that the functioning of energy clusters is aimed at using local resources, including waste, improving the quality of air and water. The expected effect is also the improvement of local power engineering security, inter alia, through the improvement of energy supply and the possibility of greater control over energy production and consumption.

\subsection{Exploitation of small hybrid installations}

Small RES installations are often used by local traders to produce energy for their own needs. Increasing public awareness, as well as among entrepreneurs in the field of environmental protection, as well as favorable forms of co-financing of RES systems, have led to the situation where small RES installations often generate more energy than their requirements. The surplus of the energy is fed into the network, which is connected to financial losses, because the energy received again in the same amount is not free of charge. Energy production within the energy cluster allows to fully utilize the generated power. Taking into account the popularity of small and micro installations of renewable energy sources, supported by additional subsidies or discounts, it is possible to successfully develop small distributed energy and include it into energy clusters. For even more effective use of the generated energy, it would be helpful to have control and monitoring systems for their hybrid systems. The more advanced systems make it possible to ensure optimal performance of the generated energy sources [10].

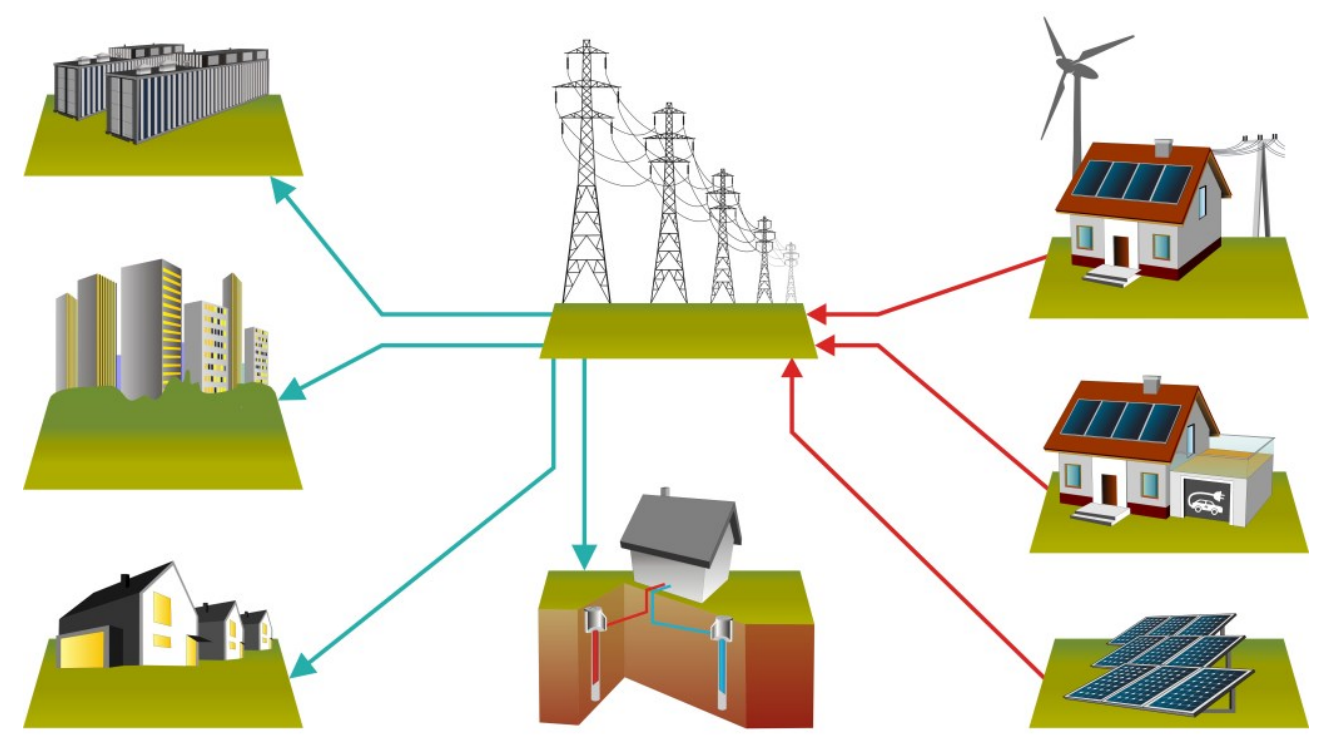

Fig. 2. The concept of functioning of small and micro installations of RES in an energy cluster. 


\subsection{Benefits of generating energy in small and micro installations}

There are many advantages and disadvantages of using small and micro installations to generate energy within clusters. Generating energy from small but numerous sources can make an important contribution to reducing the use of the energy produced by conventional power plants. Assuming that RES installations primarily produce energy for their own use, they help to improve the energy efficiency of the facilities. Gathering small energy producers in the area of the energy cluster allows for effective management of the energy flow between the producer and the consumer. Small dispersed power engineering based on emission-free and renewable energy sources has a high chance for development thanks to various forms of support and financing, both at the regional, national and EU level.

According to the report [1], most of the energy that goes into the distribution network is supplied by small hydroelectric and wind power plants. In 2018, in Poland, from above mentioned two sources, small installations introduced nearly $110 \mathrm{GWh}$ into the grid, thus producing a total of almost $120 \mathrm{GWh}$ of electricity. This is a proof that most of the installations produce energy for an external customer. In Poland, when transferring energy to the distribution network, the prosumer receives a repayment of the amount for energy reduced by $20-30 \%$ of the nominal sales amount. Introducing the same energy into the network being in the area of the energy cluster does not lose anything, because the energy is intended for cluster users. A number of simulations and studies prove that small distributed power engineering has its future in Poland, and the use of renewable energy sources will become more and more popular and will soon become a standard [11]. In the further stages of development of such type of energy, it is possible to strive to create a model of energy self-sufficiency of the areas, such as municipalities. According to the preliminary results of the simulation, it is not possible to ensure the continuous and permanent energy selfsufficiency of given areas. The analyzed cases showed that it is possible within 4 months of the year [12].

\section{Summary}

The use of small and micro installations within energy clusters has many advantages and disadvantages. Generating energy from small but multiple sources can significantly reduce the use of conventional power plants. Assuming that RES installations first and foremost produce energy for their own use, they help to improve the energy efficiency of the facilities. Energy clusters are a way to build a modern type of power industry, which exploits the potential of the region and moves away from a centralised model of professional power engineering. Of course, the growing number of energy clusters does not mean the decline of large power plants. It only changes the functioning model of the energy sector.

Energy clusters using small RES installations can be a driving force in the faster development of modern technologies such as: energy storage, smart metering, electromobility, etc. By using advanced technology of control and automation systems, we can further increase the energy efficiency of facilities [13]. Further research will focus on developing models of energy self-sufficiency of the areas. Implementation will be carried out by determining the energy demand of consumers and estimating the production capacity in micro installations operating in the area of energy clusters. Besides, the further work should focus on developing and improving the IT systems that monitor and manage the energy flow in the energy cluster area. It will provide more efficient use of generated energy in their installations. The last stage towards energy self-sufficiency will be energy storage, which is the key to the energy independence of the region. [14]. 


\section{References}

1. The URE Report, Warsaw April (2019)

2. The Act on Energy Efficiency, Dz.U. 2016, item 831, Warsaw 20.05. (2016)

3. S. Sowa, E3S Web of Conferences, 45 (2018)

4. Directive of the European Parliament and of the Council of 25 October 2012 on energy efficiency 2012/27/UE. Brussels (2012)

5. A. Alberini et al., Ecological Economics. Vol. 144, p. 171-185 (2018)

6. F. Cemil Özbuğday et al., Energy. Vol. 17, p. 734-745 (2015)

7. J. Zhang et al. Energy Procedia. Vol. 105, p. 2201-2206 (2017)

8. The Act on Renewable Energy Sources of 20.02.2015, Dz.U. 2015, item 478, Warsaw (2015)

9. B. Fraś, O. Ivashchuk, Enrgy Policy Journal, Vol. 17, p25-40 (2017)

10. S. Sowa, ICORES: Engineering, Technology, Innovation. Springer, Cham, p. 387-394 (2018)

11. R. Szczerbowski, Computer Applications in Electrical Engineering, Vol. 11, p. 416422 (2013)

12. M. Sołtysik et.al., Zeszyty Naukowe Instytutu Gospodarki Surowcami Mineralnymi i Energią

PAN, vol. 102, p. 301-312, (2018)

13. S. Sowa,. Progress in Applied Electrical Engineering, p. 1-4 (2019) p, doi: 10.1109/PAEE.2019.8788991.

14. D. Głuchy, L. Kasprzyk, A. Tomczewski.. Electrical Engineering, No 89, p. 335-345 (2017) 